\title{
Content of Calcium, Magnesium, Sodium and Potassium in the Street Dust from the Area of Białystok (Poland)
}

\author{
Mirosław Skorbiłowicz ${ }^{*}$, Elżbieta Skorbiłowicz' \\ 1 Bialystok University of Technology, Faculty of Building and Environmental Engineering; ul. Wiejska 45E, \\ 15-351 Białystok, Poland \\ * Corresponding author's e-mail: m.skorbilowicz@pb.edu.pl
}

\begin{abstract}
The aim of the study was to assess the content of $\mathrm{Ca}, \mathrm{Mg}$, $\mathrm{Na}$ and $\mathrm{K}$ in the road dust collected in Białystok from various environments (roads with high traffic intensity, housing estate roads, roads located near parks and green areas), in order to determine the impact of the road transport on the spatial differentiation of the content of the tested components in street dust and identify their main sources. In total, the samples from 69 points were analyzed, which were taken in spring 2018 (late April and May) during the dry weather. The content of $\mathrm{Ca}, \mathrm{Mg}, \mathrm{Na}$ and $\mathrm{K}$ was determined by means of atomic absorption spectrometry (AAS). The average contents of the tested elements in the dust from all measuring points were in the following order: $\mathrm{Ca}(23.53 \%)>\mathrm{Mg}(2.38)>\mathrm{Na}(1.16)$ $>\mathrm{K}(0.25)$. This shows that $\mathrm{Ca}$ is the most numerous element in the tested dusts. Studies have not shown a significant impact of vehicle traffic, in particular the so-called non-exhaust sources related to this traffic on the content of main elements in the Białystok road dusts. The analyses have indicated that the main source of $\mathrm{Ca}$ and $\mathrm{Mg}$ in the Białystok road dust constitute the structural elements of roads, bridges and structures, in which building cement and its derivatives are the main component.
\end{abstract}

Keywords: major elements, road dust, congestion.

\section{INTRODUCTION}

Road (street) dust is a loose material on the road surface resulting from the sedimentation of solid particles from the environment. The sources of road dust vary in terms of space and time (Pirjola et al., 2010; Amato et al., 2012; Chen et al., 2012). Their common sources include the processes of abrasion of brake pads and tires in motor vehicles moving on road surfaces (Denier van der Gon et al., 2012; Lee et al., 2013; Panko et al., 2013). Various types of road works and the use of salt in winter for non-slip purposes are also a common source of road dust (Kupiainen and Pirjola, 2011; Kupiainen et al., 2016). The dusts from surrounding areas bordering roads, such as arable fields, construction sites and gravel roads vary significantly depending on the geographical location, climate and season. Lower emissions occur on the roads where cars travel at a higher speed, while the emissions in the city center are higher. The temporal variability of dust emissions is also affected by the meteorological conditions, due to rainfall and high humidity inhibiting its emission (Amato et al., 2014). According to Gustafsson et al. (2019), the road dust load is usually the highest from mid-winter to early spring, while the lowest occurs in early autumn and late spring. According to Amato et al. (2017), traffic volume and vehicle speed on the street affect the amount of road dust remaining on the surface. Rexeis and Hausberger (2009) predict that the share of non-exhaust particles will constantly increase and by the end of 2020 , they will amount to approximately $90 \%$ of pollutant emissions from communication sources. The dust also includes natural materials such as leaves and other plant fragments that can be powered by traffic (Qiao et al., 2011). Road 
dust contains high levels of sulfates, chlorides, nitrogen compounds, phosphates, calcium, potassium, sodium, magnesium, and heavy metals that limit their use and management (Bartkowiak et al., 2017). The main components of road dusts are $\mathrm{Ca}, \mathrm{C}, \mathrm{Al}, \mathrm{Mg}, \mathrm{Fe}, \mathrm{S}, \mathrm{K}$ and $\mathrm{Na}$ (Jancsek-Turczi, 2013). A similar set of components was also shown by other studies (Vega et al., 2001, Zhao et al., 2006). The high Ca content in road dust in cities can indicate a large impact of anthropogenic emissions such as construction work. The $\mathrm{Ca} / \mathrm{Al}$ ratio can be taken as an indicator to distinguish the geological sources from the urban or extra-urban areas (Liu et al., 2016). Shen et al. (2016) used this indicator to track the urban dust sources from local or longrange transport. The subject of this study is the street dust testing based on the material collected in Bialystok. Białystok (294 153 inhabitants) is a city located in the north-eastern part of Poland. It is not a large enough to develop its transport infrastructure including metro or trams; there are only the public transport buses. The street dust studies have not yet been carried out in Bialystok, only the content of trace elements in urban soil was tested.

The aim of the study was to assess the content of $\mathrm{Ca}, \mathrm{Mg}, \mathrm{Na}$ and $\mathrm{K}$ in road dust collected in Białystok from various environments (roads with high traffic intensity, housing estate roads, roads located near parks and green areas), in order to determine the impact of road transport on the spatial differentiation of the content of tested components in street dust and identify their main sources.

\section{RESEARCH METHODOLOGY}

\section{Study area}

The city of Białystok $\left(53^{\circ} 07^{\prime} 59^{\prime \prime} \mathrm{N}\right.$ and $\left.23^{\circ} 09^{\prime} 51^{\prime \prime} \mathrm{E}\right)$ is located in the north-eastern Poland and covers an area of $102.12 \mathrm{~km}^{2}$. There are 294153 inhabitants in Białystok and the population density is 2880 people per $\mathrm{km}^{2}$. The largest area in the land use structure is occupied by the built-up and urbanized land, and about $32 \%$ of the city is covered by green areas. The city has the most park forests in the southern and northern parts of the city. The city has a moderate climate with the following annual averages: temperature $6.6^{\circ} \mathrm{C}$, precipitation $586 \mathrm{~mm}$, wind speed $10.1 \mathrm{~km} \cdot \mathrm{h}^{-1}$. Brown and podzolic soils are dominant in the city.

\section{Sampling and sample preparation}

The research points were divided into three groups: high congestion (13 680-30 720 vehicles per day), small congestion - housing estate roads (4 800-18 000 vehicles per day) and potentially non-polluted areas where there is potentially no heavy traffic - around parks and areas green (2 640-9 120 vehicles per day). In total, the samples from 69 points were analyzed (Figure 1), which were taken in spring (late April and May) during the dry weather in 2018. The road dust was collected from both sides of the road lane at the curbs. The area from which the samples were taken was one square meter $\left(1 \mathrm{~m}^{2}\right)$. The samples were collected by sweeping about $500 \mathrm{~g}$ of material

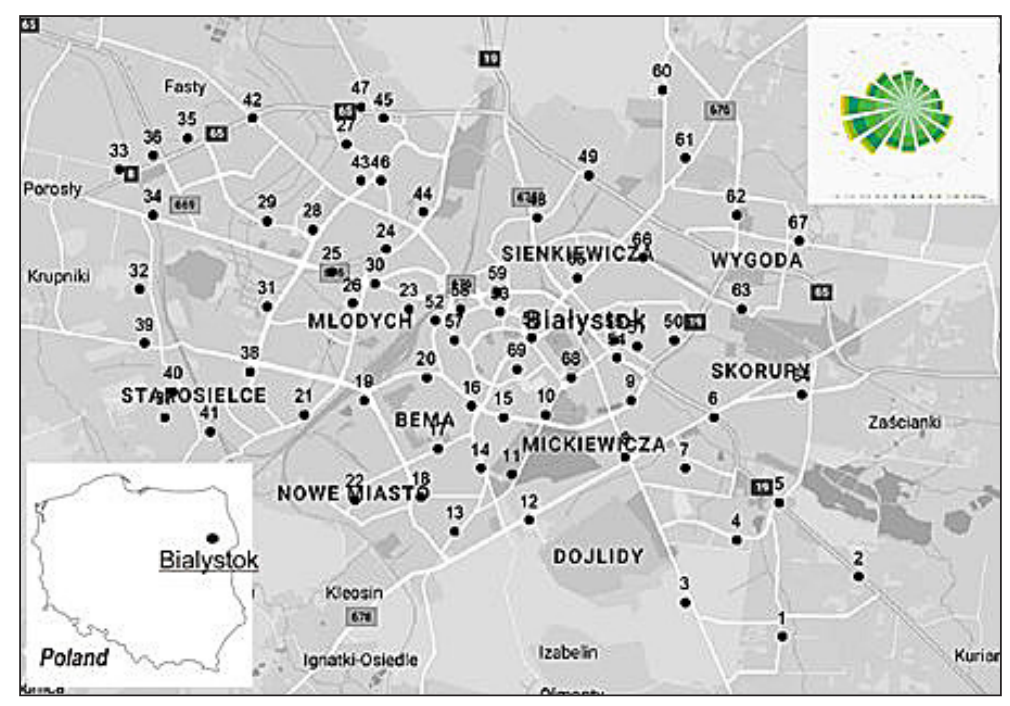

Figure 1. Location of the studied area with 69 measuring points and a wind map showing the prevailing wind direction in Bialystok 
with a brush and a clean plastic scoop into plastic self-sealing polyethylene bags and subsequently transporting it to the laboratory. Then, the street dust was dried in the laboratory at room temperature. After drying, it was sieved through a $1 \mathrm{~mm}$ nylon sieve to remove large stones and plant debris, then again dried in an oven at $110^{\circ} \mathrm{C}$. The dried samples were ground in an automatic agate mortar. All sampling and handling procedures were carried out without contact with metals to avoid potential contamination.

\section{Analytical procedures}

The street dust in the amount of $0.5 \mathrm{~g}$ was mineralized with hydrochloric and nitric acid in a 3:1 volume ratio in a closed microwave system. All determinations were performed in triplicate. The samples after filtration were transferred quantitatively into $50 \mathrm{ml}$ graduated flasks. The content of $\mathrm{Ca}, \mathrm{Mg}$, $\mathrm{Na}$ and $\mathrm{K}$ was determined by means of atomic absorption spectrometry (AAS) on an AAS ICE 3500 Thermo Scientific spectrometer. All solutions were prepared using ultra-pure water. The glassware used for the determination was soaked in nitric acid (8\%) and washed with tap water, followed by thorough rinsing with deionized water. The results of the street dust analyses were verified using the certified reference material (Certificate No. 0217-CM-700I-04, 7003). The measurement results of standard reference material showed good compliance with the certified values. The obtained results pertaining to the contents of tested $\mathrm{Ca}, \mathrm{Mg}, \mathrm{Na}$ and $\mathrm{K}$ are given in relation to air-dry dusts.

\section{Statistical analysis}

All statistical analyses were performed using the licensed Statistica software - ver. 13.3 for Windows. The Shapiro-Wilk test was used to verify normal distribution. The results were considered statistically significant with a probability of error $p<0.05$. The Spearman's correlation analysis was used to investigate the relationship between metals in road dust and identify their sources. The correlation coefficient was used to measure the interrelationships between two metals. Multivariate statistical analysis (PCA) was also used for the analysis, which is often applied to identify the sources of dust pollution (Lu et al. 2010; Chen et al. 2011). The statistical cluster analysis (CA) in the Ward version was used to classify the metals from various sources but with similar physical and chemical properties (Christoforidis and Stamatis, 2009).

\section{RESULTS AND DISCUSSION}

Four major elements were tested ( $\mathrm{Ca}, \mathrm{Mg}, \mathrm{Na}$ and $\mathrm{K}$ ) in 69 samples of road dust collected in Białystok along streets with high and low traffic in Table 1.

The tests of the main elements $\mathrm{Ca}, \mathrm{Mg}, \mathrm{Na}$ and $\mathrm{K}$ in 69 samples of the road dust collected in Bialystok along roads with high and low traffic intensity and in the areas potentially not contaminated with metals from car transport are presented in Table 1. It was found that the average content of elements in road dusts assume the following order: $\mathrm{Ca}>\mathrm{Mg}>\mathrm{Na}>\mathrm{K}$. The average content of $\mathrm{Ca}$, $\mathrm{Mg}$ and $\mathrm{Na}$ in the dusts from all examined areas were similar except for $\mathrm{K}$, the content of which in the dusts from potentially unpolluted area was more than twice higher $(0.46 \%)$ than its content in the dusts from areas with high $(0.21 \%)$ and small congestion $(0.21 \%)$. Around the potentially unpolluted areas, there are large areas of lawns, shrubs and trees, which can increase the contact of road dust with the soil present there. The research conducted by Pakuła and Kalembasa (2012) shows that the K content in soils is very similar to its content in the road dust. The results of the research achieved in this paper confirmed this relationship.

The largest differences occurred between the values of the variation coefficients for $\mathrm{Ca}, \mathrm{Mg}$ and $\mathrm{Na}, \mathrm{K}$ in each area studied. The $\mathrm{Na}$ and $\mathrm{K}$ coefficients of variation were about 2-4 times higher in each area than the $\mathrm{Ca}$ and $\mathrm{Mg}$ coefficients. At the same time, normal distributions of the $\mathrm{Ca}$ and $\mathrm{Mg}$ content were found, in contrast to $\mathrm{Na}$ and $\mathrm{K}$, for which no such distributions were present. On the other hand, $\mathrm{Na}$ and $\mathrm{K}$ are characterized by high variability, which may indicate their more anthropogenic nature.

The Ca content in the road dust from Białystok ranged from $1.13 \%$ to $38.11 \%$. These were higher amounts of this element than those from the studies by Ordonez et al. (2002) for the dust in the city of Aviles (Spain) (9.08\%-12.0\%). Similarly as in the case of $\mathrm{Ca}$, there was also higher $\mathrm{Mg}$ content in the Białystok dust ranging from $0.29 \%$ to $4.52 \%$, in comparison with the dust from Aviles, where the $\mathrm{Mg}$ content was in the range 
Table 1. Descriptive statistics of major elements concentrations in road dusts of Bialystok

\begin{tabular}{|c|c|c|c|c|c|}
\hline \multicolumn{2}{|c|}{ Major element $(\%)$} & $\mathrm{Ca}$ & $\mathrm{Mg}$ & $\mathrm{Na}$ & $\mathrm{K}$ \\
\hline \multirow{6}{*}{$\begin{array}{l}\text { large } \\
\text { congestion } \\
n=32\end{array}$} & Min & 2.63 & 0.29 & 0.05 & 0.03 \\
\hline & Max & 38.11 & 4.52 & 5.65 & 1.29 \\
\hline & Mean & 21.80 & 2.37 & 1.04 & 0.21 \\
\hline & SD & 9.73 & 0.90 & 1.17 & 0.30 \\
\hline & $\mathrm{CV}[\%]$ & 44.6 & 37.9 & 111.8 & 147,0 \\
\hline & S-W test & 0.16 & 0.92 & 0.01 & 0.01 \\
\hline \multirow{6}{*}{$\begin{array}{l}\text { small congestion } \\
n=26\end{array}$} & Min & 7.58 & 1.44 & 0,04 & 0.01 \\
\hline & Max & 38,33 & 3.47 & 5.90 & 1.16 \\
\hline & Mean & 25.98 & 2.34 & 1.25 & 0.21 \\
\hline & SD & 6.80 & 0.66 & 1.30 & 0.27 \\
\hline & $\mathrm{CV}[\%]$ & 26.2 & 28.2 & 103.5 & 125.4 \\
\hline & S-W test & 0.60 & 0.41 & 0.01 & 0.01 \\
\hline \multirow{6}{*}{$\begin{array}{l}\text { parks and green } \\
\text { areas } \\
n=11\end{array}$} & Min & 1.13 & 1.14 & 0.33 & 0.01 \\
\hline & Max & 34.03 & 3.47 & 6.72 & 1.78 \\
\hline & Mean & 23.18 & 2.38 & 1.34 & 0.46 \\
\hline & SD & 10.12 & 0.70 & 1.87 & 0.60 \\
\hline & $\mathrm{CV}[\%]$ & 43.7 & 29.3 & 140.0 & 130.5 \\
\hline & S-W test & 0.07 & 0.58 & 0.01 & 0.01 \\
\hline
\end{tabular}

from $0.94 \%$ to $1.28 \%$. The research by Zawadzki (1999) showed the Na content in the Polish soils ranging from $0.18 \%$ to $0.37 \%$. The content of $\mathrm{Na}$ in the road dusts from Białystok ranged from $0.04 \%$ to $6.72 \%$; thus, their range is much wider than the range in soils. In this case, the use of agents containing large amounts of salt for deicing the street surfaces has the greatest impact on the formation of the $\mathrm{Na}$ content in the tested dusts. In comparison with the Na content (0.03-0.05\%) in the road dust in Aviles (Ordonez et al. 2002), the Na content in the dust from Białystok is much higher. The tests showed a similar $\mathrm{K}$ content in the Białystok dust $(0.01 \%-1.78 \%)$ and Polish soils $(0.01 \%-2.00 \%)$. The road dust in the city of Aviles showed lower $\mathrm{K}$ contents ranging from $0.09 \%$ to $0.23 \%$. As shown in Table 1 , the congestion does not significantly affect the content of the main elements in the Białystok road dust, as opposed to e.g. heavy metals, the tests of which were carried out by the authors of this work. Other studies indicate that the formation of yjr $\mathrm{Na}$, $\mathrm{Mg}$ and $\mathrm{Ca}$ content in the road dust from high traffic areas may be related to the movement of vehicles, coal combustion, road pavement materials and the use of deicing materials (Yatkin and Bayram, 2008; Bućko et al., 2010).

The Spearman correlations between the tested elements in the street dust are presented in Table 2. The analyses showed a significant correlation of $\mathrm{Ca}$ and $\mathrm{Mg}$ at the level of $\mathrm{r}=0.66$, which may indicate common sources of both elements related, among others, with the construction works carried out on the examined roads. $\mathrm{Ca}$ and $\mathrm{Mg}$ are common components of all types of building cements used to build roads, bridges and building components. These are factors inseparably associated with streets (roads) affecting the content of $\mathrm{Ca}$ and $\mathrm{Mg}$ in dust. Due to the above, the demonstrated variability of $\mathrm{Ca}$ and $\mathrm{Mg}$ in dusts was at a fairly even level. However, no significant correlation was found between $\mathrm{Na}$ and $\mathrm{K}$, which may indicate a lack of a common source of both elements. As previously noted, an important source of $\mathrm{Na}$ in the Białystok dust are the activities related to the removal of icing - sprinkling salt on road surfaces. The main salt component is primarily Na, less often $\mathrm{K}$. The main source of $\mathrm{K}$ includes the soils surrounding roads and streets, in particular those occurring in the areas of parks, forests and potentially unpolluted areas.

Development of the statistical data using PCA allowed for the identification of potential

Table 2. Spearman's correlations matrix for the major elements concentrations. Correlation is significant at the 0.05 level

\begin{tabular}{|c|c|c|c|c|}
\hline & $\mathrm{Ca}$ & $\mathrm{Mg}$ & $\mathrm{Na}$ & $\mathrm{K}$ \\
\hline $\mathrm{Ca}$ & 1,00 & & & \\
\hline $\mathrm{Mg}$ & 0,66 & 1,00 & & \\
\hline $\mathrm{Na}$ & $-0,14$ & $-0,11$ & 1,00 & \\
\hline $\mathrm{K}$ & $-0,08$ & 0,05 & 0,38 & 1,00 \\
\hline
\end{tabular}


sources of main elements (Table 3). Table 3 shows two factors explaining a total of $83 \%$ of variation. Factor 1 is the most important, because it explains most of the variation $(50 \%)$ and is correlated with $\mathrm{Na}$ and $\mathrm{K}$. As previously noted, the sources of $\mathrm{Na}$ and $\mathrm{K}$ are salt sprinkling operations to remove icing on road surfaces. The second factor is already less important, because it explains $33 \%$ of the variance and indicates the origin of $\mathrm{Ca}$ and $\mathrm{Mg}$ from road elements, structures and bridges.

The study also uses the cluster analysis in the Ward version based on measuring the distance of Euclidean similarities (Yongming et al. 2006; Lu et al. 2010). In Figure 2, three groups are distinguished: group $1(\mathrm{Ca})$, group $2(\mathrm{~K}, \mathrm{Na}$ and $\mathrm{Mg})$, group $3(\mathrm{~K}$ and $\mathrm{Na}$ ). Classification of the main elements was largely dependent on their content, which had its own range for each class. In group 1, the highest content of $\mathrm{Ca}$ was noted, and in group 3, the lowest content of $\mathrm{Na}$ and $\mathrm{K}$.

Table 3. The rotated component matrix for data of metals in street dusts of Bialystok $(n=69)$. Principal factors $>0.7$ are selected in each column

\begin{tabular}{|c|c|c|}
\hline Variables & Factor 1 & Factor 2 \\
\hline $\mathrm{Ca}$ & $-0,16$ & $\mathbf{0 , 8 8}$ \\
\hline $\mathrm{Mg}$ & $-0,02$ & $\mathbf{0 , 9 1}$ \\
\hline $\mathrm{Na}$ & $\mathbf{0 , 9 1}$ & $-0,13$ \\
\hline $\mathrm{K}$ & $\mathbf{0 , 9 3}$ & $-0,06$ \\
\hline \% of variance & 50 & 33 \\
\hline
\end{tabular}

\section{CONCLUSIONS}

The average contents of the tested elements in the dust from all measuring points were in the following order: $\mathrm{Ca}(23.53 \%)>\mathrm{Mg}(2.38)>\mathrm{Na}$ (1.16) $>\mathrm{K}(0.25)$. This shows that $\mathrm{Ca}$ is the most numerous element in the tested dusts. Studies have not shown a significant impact of vehicle traffic, in particular the so-called non-exhaust sources related to this traffic on the content of main elements in the Białystok road dusts. The analyses have shown that the main source of $\mathrm{Ca}$ and $\mathrm{Mg}$ in the Białystok road dust includes structural elements of roads, bridges and structures, in which building cement and its derivatives are the main component. However, the main source of $\mathrm{Na}$ and $\mathrm{K}$ in the tested dusts involves the activities related to sprinkling salt and roads in winter in order to deice them. Considering literature reports, the $\mathrm{Na}$ and $\mathrm{K}$ content in road dusts are seasonal. Therefore, their content found in the spring may reach their maximum in comparison with, for example, the autumn and winter period. A fairly common source of main elements in the studied material corresponds to the soils surrounding the roads and streets, from which, as the research shows, the most potassium originate.

\section{Acknowledgements}

The research was carried out as part of research project no. WZ/WBiIŚ/8/2019 at Białystok University of Technology and financed from a subsidy provided by the Minister of Science and Higher Education.

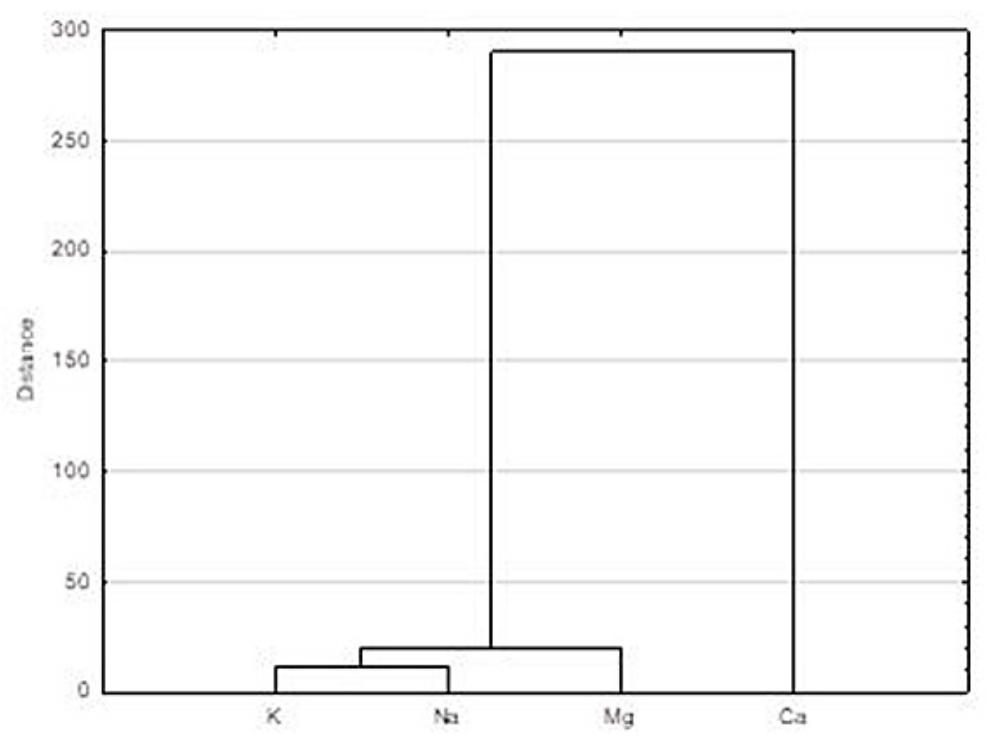

Figure 2. Hierarchical dendrograms for heavy metals in dust obtained by Ward's hierarchical clustering method 


\section{REFERENCES}

1. Amato, F., Bedogni, M., Padoan, E., Querol, X., Ealo, M., Rivas, I., 2017. Characterization of road dust emissions in Milan: impact of vehicle fleet speed. Aerosol and Air Quality Research 17, 24382449. https://doi.org/10.4209/aaqr.2017.01.0017.

2. Amato, F., Cassee, F.R.C., van der Gon, H.A., Hafner, W., Gehrig, R., et al., 2014. Urban air quality: The challenge of traffic non-exhaust emissions. Journal of Hazardous Materials, 275, 31-36. doi. org/10.1016/j.jhazmat.2014.04.053.

3. Amato, F., Schaap, M., Denier van der Gon, H.A.C., Pandolfi, M., Alastuey, A., Keuken, M., Querol, X., 2012. Effect of rain events on the mobility of road dust load in two Dutch and Spanish roads. Atmos. Environ. 62, 352-358. https://doi.org/10.1016/j. atmosenv.2012.08.042.

4. Bartkowiak, A., Dąbkowska-Naskręt, H., Lemanowicz, J., Siwik-Ziomek, A., 2017. Assessment of physicochemical and biochemical factors of urban street dust. Environment Protection Engineering, Vol. 43, No. 3, 155-164

5. Bućko, M.S.; Magiera, T.; Pesonen, L.J.; Janus, B. Magnetic, geochemical, and microstructural characteristics of road dust on roadsides with different traffic volumes-Case study from Finland. Water Air Soil Pollut. 2010, 209, 295-306.

6. Chen, J., Wang, W., Liu, H., Ren, L., 2012. Determination of road dust loadings and chemical characteristics using resuspension. Environ. Monit. Assess. 184, 1693-1709. https://doi.org/10.1007/ s10661-011-2071-1.

7. Chen, J.Q., Wang, Z.X., Wu, X., Zhu, J.J., Zhou, W.B., 2011. Source and hazard identification of heavy metals in soils of Changsha based on TIN model and direct exposure method. T Nonferr Metal Soc 21(3):642- 651

8. Christoforidis A, Stamatis N, (2009) Heavy metal contamination in street dust and roadside soil along the major national road in Kavala's region, Greece, Geoderma 151, 257-263.

9. Denier van der Gon, H., Gerlofs-Nijland, M.E., Gehrig, R., Gustafsson, M., Janssen, N., Harrison, R.M., Hulskotte, J., Johansson, C., Jozwicka, M., Keuken, M., Krijgsheld, K., Ntziachristos, L., Riediker, M., Cassee, F.R., 2012. The policy relevance of wear emissions from road Transport, now and in the future - an international workshop report and consensus statement. J. Air Waste Manag. Assoc. 63, 136-149. https://doi. org/10.1080/10962247.2 012.741055 .

10. Gustafsson M., Blomqvista G., Järlskoga I., Lundberga J., Janhällb S., Elmgrenc M., Johanssonc Ch., Normanc M., Silvergrenc S. 2019. Road dust load dynamics and influencing factors for six winter seasons in Stockholm, Sweden. Atmospheric Environment X2. https://doi.org/10.1016/j. aeaoa.2019.100014.

11. Jancsek-Turóczi B., Hoffer A., Nyírö-Kósa I., Gelencsér A. 2013. Sampling and characterization of resuspended and respirable road dust. Journal of Aerosol Science. 65 69-76.

12. Kupiainen, K., Ritola, R., Stojiljkovic, A., Pirjola, L., Malinen, A., Niemi, J., 2016. Contribution of mineral dust sources to street side ambient and suspension PM10 samples. Atmos. Environ. 147, 178-189. https://doi.org/10.1016/j.atmosenv.2016. 09.059 .

13. Kupiainen, K.J., Pirjola, L., 2011. Vehicle non-exhaust emissions from the tyre-road interface-effect of stud properties, traction sanding and resuspension. Atmos. Environ. 45, 4141-4146. https://doi. org/10.1016/j.atmosenv.2011.05.027.

14. Lee, S., Kwak, J., Kim, H., Lee, J., 2013. Properties of roadway particles from interaction between the tire and road pavement. Int. J. Automot. Technol. 14, 163-173. https:// doi.org/10.1007/ s12239-013-0018-y.

15. Liu Y., Zhang W., Bai Z., Yang W., Zhao X., Han B., Wang X. 2016. Characteristics of PM10 Chemical Source Profiles for Geological Dust from the South-West Region of China. Atmosphere, 7(11),146; https://doi.org/10.3390/ atmos 7110146

16. Lu, X., Wang, L., Li, L.Y., Lei, K., Huang, L., Kang, D., 2010. Multivariate statistical analysis of heavy metals in street dust of Baoji NW China. J Hazard Mat, 173(1-3):744-749.

17. Pakuła K., Kalembasa K. 2012. Makroelementy w glebach ornych Wysoczyzny Siedleckiej. Acta Agrophysica. 19(4), 803-814.

18. Panko, J.M., Chu, J., Kreider, M.L., Unice, K.M., 2013. Measurement of airborne concentrations of tire and road wear particles in urban and rural areas of France, Japan, and the United States. Atmos. Environ. 72, 192. https://doi.org/10.1016/j. atmosenv.2013.01.040.

19. Pirjola, L., Johansson, C., Kupiainen, K., Stojiljkovic, A., Karlsson, H., Hussein, T., 2010. Road dust emissions from paved roads measured using different mobile systems. J.Air Waste Manag. Assoc. 60, 1422-1433. https://doi. org/10.3155/1047-3289.60.12. 1422.

20. Qiao, Q., Zhang, C., Huang, B., Piper, J. D. A., 2011. Evaluating the environmental quality impact of the 2008 Beijing Olympic Games: magnetic monitoring of street dust in Beijing Olympic, Park Geophys. J. Int. 187, 1222

21. Rexeis, M., Hausberger, S., 2009. Trend of vehicle emission levels until 2020-Prognosis based on current vehicle measurements and future 
emission legislation. Atmospheric Environment, 43, 4689-4698

22. Shen, Z., Jian, S., Cao, J., Zhang, L., Qian, Z., Lei, Y., Gao, J., Huang, RJ., Liu, S., Yu, H. 2016. Profile chemiczne próbek ulotnego pyłu miejskiego PM 2,5 w miastach północnych Chin. Sci. Total Environ. 569-570, 619-626.

23. Vega, E., Mugica, V., Reyes, E., Sanchez, G., Chow, J.C., \& Watson, J.G. (2001). Chemical composition of fugitive dust emitters in Mexico City. Atmospheric Environment, 35, 4033-4039.
24. Yatkin, S.; Bayram, A. Determination of major natural and anthropogenic source profiles for particulate matter and trace elements in Izmir, Turkey. Chemosphere 2008, 71, 685-696.

25. Yongming H, Peixuan D, Junji C, Posmentier ES (2006) Multivariate analysis of heavy metal contamination in urban dusts of Xi'an, Central China. Sci Total Environ 355:176-186

26. Zhao, P., Feng, Y., Zhu, T., \& Wu, J. (2006). Characterizations of resuspended dust in six cities of North China. Atmospheric Environment, 40, 5807-5814. 